Conservation Co-Benefits from Air Pollution Regulation: Evidence from Birds

Yuanning Liang, Ivan J. Rudik, Eric Zou, Alison Johnston, Amanda D. Rodewald, and Catherine L. Kling

NBER Working Paper No. 27415

June 2020, Revised in August 2020

JEL No. Q53,Q57,Q58

\begin{abstract}
Massive wildlife losses over the past 50 years have brought new urgency to identifying both the drivers of population decline and potential solutions. We provide the first large-scale evidence that air pollution, specifically ozone, is associated with declines in bird abundance in the United States. We show that an air pollution regulation limiting ozone precursors emissions has delivered substantial benefits to bird conservation. Our estimates imply that air quality improvements over the past four decades have stemmed the decline in bird populations, averting the loss of 1.5 billion birds, approximately 20 percent of current totals. Our results highlight that in addition to protecting human health, air pollution regulations have previously unrecognized and unquantified conservation co-benefits.

Yuanning Liang

Cornell University

y12544@cornell.edu

Ivan J. Rudik

Cornell University

Dyson School of Applied Economics

and Management

SC Johnson College of Business

Cornell University

Ithaca, NY 14853

irudik@cornell.edu

Eric Zou

Department of Economics

University of Oregon

1415 Kincaid Street

Eugene, OR 97403

and NBER

ericzou@uoregon.edu

\author{
Alison Johnston \\ Cornell University \\ Cornell Lab of Ornithology \\ aj327@cornell.edu \\ Amanda D. Rodewald \\ Cornell University \\ Department of Natural Resources \\ arodewald@cornell.edu \\ Catherine L. Kling \\ Cornell University \\ 464 Warren Hall \\ Ithaca, NY 14853 \\ ckling@cornell.edu
}




\title{
Conservation Co-Benefits from Air Pollution Regulation: Evidence from Birds
}

\author{
Yuanning Liang ${ }^{1, \dagger}$ \\ Ivan Rudik ${ }^{1, \dagger, *}$ \\ Eric $\mathrm{Zou}^{2,3 \dagger}$ \\ Alison Johnston ${ }^{4}$ \\ Amanda D. Rodewald ${ }^{4,5}$ \\ Catherine L. Kling ${ }^{1}$
}

August 2020

\begin{abstract}
Massive wildlife losses over the past 50 years have brought new urgency to identifying both the drivers of population decline and potential solutions. We provide the first large-scale evidence that air pollution, specifically ozone, is associated with declines in bird abundance in the United States. We show that an air pollution regulation limiting ozone precursors emissions has delivered substantial benefits to bird conservation. Our estimates imply that air quality improvements over the past four decades have stemmed the decline in bird populations, averting the loss of 1.5 billion birds, approximately 20 percent of current totals. Our results highlight that in addition to protecting human health, air pollution regulations have previously unrecognized and unquantified conservation co-benefits.
\end{abstract}

${ }^{1}$ Charles H. Dyson School of Applied Economics and Management, Cornell University.

${ }^{2}$ Department of Economics, University of Oregon.

${ }^{3}$ National Bureau of Economic Research.

${ }^{4}$ Cornell Lab of Ornithology, Cornell University.

${ }^{5}$ Department of Natural Resources, Cornell University.

*Materials and correspondence: irudik@cornell.edu

$\dagger$ These authors equally contributed to this work. We thank Trudy Cameron, Chris Costello, David Evers, Andrew Farnsworth, Sonja Kolstoe, Kenneth Rosenberg, and seminar participants at the Cornell Lab of Ornithology for comments and suggestions. We thank Marley Bonacquist-Currin and Angela Zeng for research assistance. 
Air pollution is widely recognized as a leading cause of human morbidity and mortality (e.g., Dockery et al., 1993; Pope et al., 2002; Chen et al., 2013; Dominici, Greenstone, and Sunstein, 2014; Schlenker and Walker, 2016; Landrigan et al., 2018; Deryugina et al., 2019). Regulation of anthropogenic emissions, especially the combustion of fossil fuels, is key to alleviating global health burdens from pollution exposure. Indeed, air pollution policies, such as the United States' Clean Air Act, have improved ambient air quality, reduced disease incidence, and increased life expectancy (e.g., Chay, Dobkin, and Greenstone, 2003; Deschênes, Greenstone, and Shapiro, 2017). Quantifying the impacts of both pollution exposure and regulation has been largely restricted to humans, and our understanding of benefits to non-human species - many of which are sensitive to pollution - remains poor. The physiology and unique respiratory systems of birds, in particular, should make them especially susceptible to air pollution (Rombout et al., 1991; Brown et al., 1997; Cuesta et al., 2005; Sanderfoot and Holloway, 2017). For this reason, birds are a useful focal taxon to examine how policy interventions for air pollution may deliver broader benefits to ecosystems.

We provide the first continental-scale evidence that ground-level ozone negatively affects the North American avifauna, a group of animals that are well-known indicators of environmental health and one of the only groups for which abundance data are available at fine resolution across broad spatial and temporal scales (Morrison, 1986; Gregory et al., 2003; Niemi and McDonald, 2004; Burger and Gochfeld, 2014). We then analyze how the U.S. Environmental Protection Agency (EPA) NOx Budget Trading Program (NBP), an air quality regulation that was designed to protect human health by limiting summertime emissions of ozone precursors from large industrial sources, has provided substantial conservation co-benefits for avifauna.

Current understanding of the impact of air pollution on birds is limited to case- or laboratory-based studies on the toxicology of pollution exposure, whereas species- or continental-scale impacts are largely unknown (Newman, 1979; Rombout et al., 1991; Llacuna et al., 1993; Gilmour et al., 2001; Loomis et al., 2013; Sanderfoot and Holloway, 2017; Isaksson et al., 2017; Salmon et al., 2018). We expand the spatial and temporal lens of previous studies to better understand the extent to which pollution contributed to population declines in North American birds, which have lost a staggering 2.9 billion breeding individuals over the last 50 years (Rosenberg et al., 2019). A rough 
calculation based on our estimated ozone response suggests that observed declines in bird populations would have been 50 percent greater in the absence of reductions in ground-level ozone since 1980. In short, the regulation of ozone has led to an additional 1.5 billion birds, approximately $20 \%$ of current populations.

There are several ways in which ozone is expected to harm individual birds in ways that can scale up to affect population size and trends. High levels of ozone can directly impact birds via physical harm, such as damage to respiratory systems, or indirectly via changes to habitat conditions, food supplies, and/or species interactions. There exists strong evidence that elevated ozone reduces primary productivity, inhibits growth rate and biomass of plants (especially deciduous trees), reduces plant species richness and community composition, chemically impedes plant-pollinator interactions, changes foliar quality and content of nitrogen, increases plant susceptibility to damage and disease, impacts soil microbial communities, and increases secondary (defensive) plant compounds to reduce herbivory by insects, which in turn have lower biomass and higher rates of mortality (Agathokleous et al., 2020). For example, the literature shows that ozone damages plants in ways that affect growth, architecture, and chemical composition, including the secondary compounds used to defend against herbivory from insects. Likewise, Hillstrom and Lindroth (2008) reported 17\% lower arthropod abundance when ozone levels were elevated compared to normal ambient levels which may harm insectivorous birds. When access to highquality habitat or food resources is reduced, mortality of individuals (adults, juveniles, nestlings) may increase due to immediate health consequences or longer-term impacts that carry over across seasons. For example, a bird that has insufficient energetic reserves is more likely to die during migration, which reduces the population by way of the loss of that individual and its future reproductive productivity. Even in less severe cases, that individual may produce fewer young than it would have otherwise.

Our analysis is based on bird observations across the contiguous United States between 2002 and 2016, derived from over 11 million eBird checklists (Sullivan et al., 2009). Following Sauer and Link (2019) and Rosenberg et al. (2019), we develop a statistical model to estimate changes in bird abundance over time, based on the counts of birds reported. We model the count of birds in each eBird checklist, whilst accounting for effects of observer effort (e.g. hours spent amassing 
observations), and bird detectability (e.g., time of day) (Fig.1). The supplementary information documents the consistency of our findings with other approaches and their robustness to our modeling choices. While these adjustments do not estimate actual population sizes, they do generate data on the relative abundance of bird populations. By studying how the relative abundance of birds is affected by pollution, we can infer the impacts on absolute abundance by combining our estimates with independent estimates on bird population sizes.

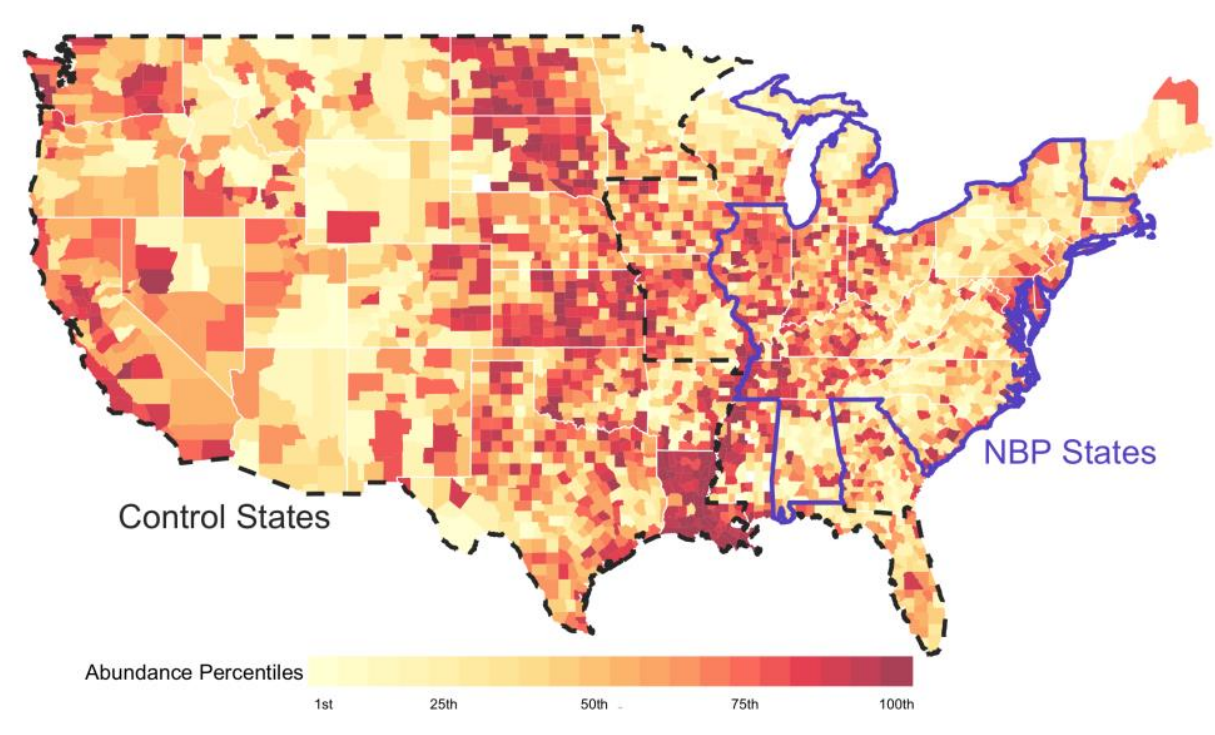

Fig. 1. The spatial distribution of bird abundance. County colors indicate ventiles of bird abundance across all years. Darker colors indicate greater abundance. The set of states outlined in solid blue are those subject to the $\mathrm{NO}_{\mathrm{x}}$ Budget Trading Program (NBP). The set of states outlined in dashed black are the control states. The states not within the blue or black areas are omitted from the analysis due to potential atmospheric transport of pollution (Deschenes, Greenstone, and Shapiro, 2017). The states omitted from the $\mathrm{NO}_{\mathrm{x}}$ Budget Trading Program analysis are Georgia, Iowa, Maine, Mississippi, Missouri, New Hampshire, Vermont, and Wisconsin.

The abundance estimates are combined with the U.S. EPA's ground-level pollution monitor readings and states' pollution regulation information. These data allow us to construct a longitudinal database that tracks month-over-month changes in bird abundance, air quality, and regulation status for 3,214 counties over a 15-year timespan. The longitudinal nature of our data allows us to identify the effect of air pollution using a "within" estimator that links a county's changes in bird abundance to changes in air pollution. We use a research design that flexibly accounts for spatial (3,214 counties), temporal (15 years), and seasonal (12 calendar months) patterns in the data, constructing a three-way interactive fixed effects estimator that controls for 
all observable and unobservable confounding factors within a county-year, season-year, and county-season. Specifically, county-year fixed effects control for differences in attributes across counties within each year, such as conservation policies or land use (e.g., impervious surfaces, forest, cropland). Season-year fixed effects control for changes in a season from one year to the next that are common across all counties, such as changes in average summer ozone or mean abundance of breeding birds. Finally, county-season fixed effects control for all county-specific seasonal trends, such as local seasonal variation in observer activity and seasonal trends in bird abundance due to migration. We also control for contemporaneous changes in weather elements including temperature and precipitation. The weather controls and the rich set of fixed effects control for a large set of (potentially unobservable) ecologically-relevant factors that affect abundance, leaving variation in pollution that is as good as random. Importantly, the focus on changes or trends in relative abundance rather than absolute number of birds allows us to track the abundance-pollution relationship without having to estimate population sizes. We discuss estimation details assumptions in supplementary information.

A
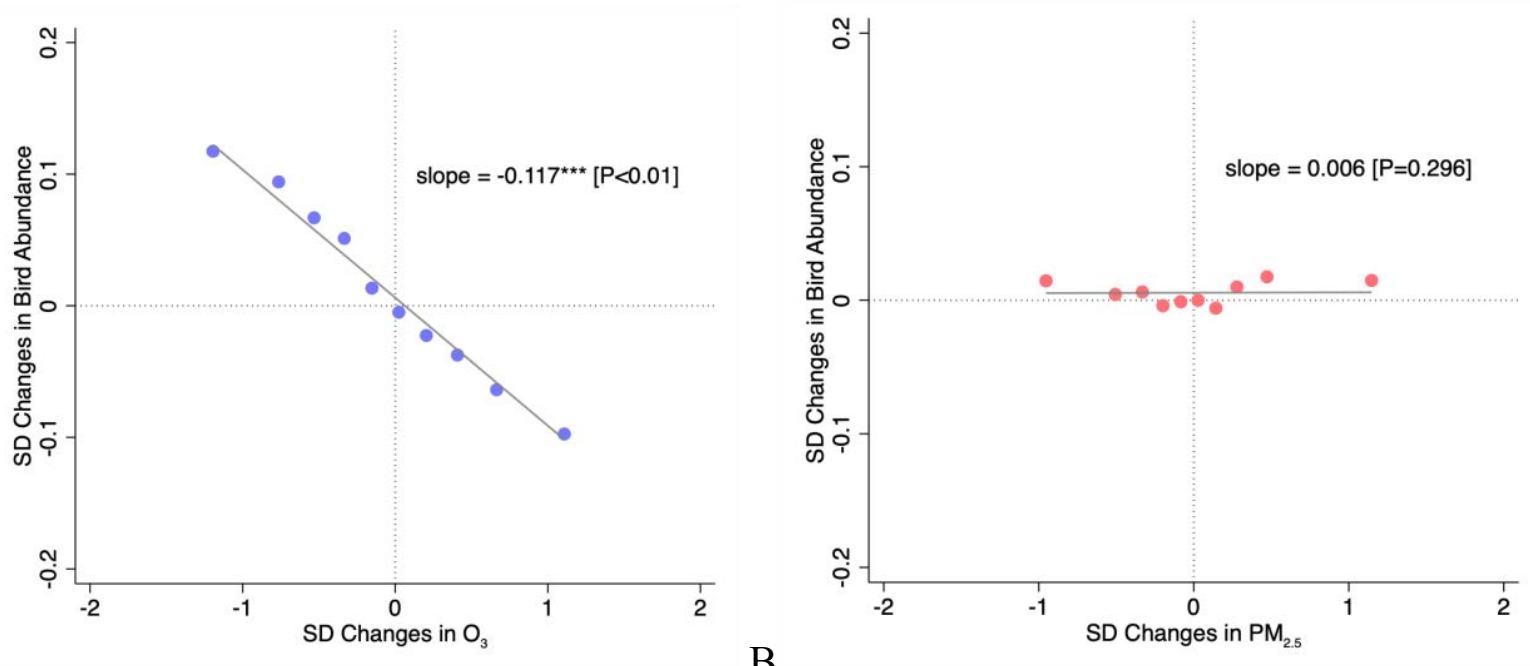

Fig. 2. The association between bird abundance and different pollutants. The two panels correspond to ozone (A) and fine particulate matter (B). The line is the estimated best fit line from a linear regression of bird abundance on both pollutants, weather variables, and fixed effects. The points correspond to the mean values of the pollutant and bird abundance within each pollutant decile after removing the effect of the other pollutant, weather variables, and fixed effects. Standard errors are clustered at the state-season level and robust to heteroskedasticity. The regressions are weighted by the number of checklists in a given county-year-month. $\quad * * * \mathrm{p}<$ $0.01,{ }^{* *} \mathrm{p}<0.05, * \mathrm{p}<0.10$. The number of observations is 92,072 . 
We estimate the effect of ozone $\left(\mathrm{O}_{3}\right)$ and fine particulate matter $\left(\mathrm{PM}_{2.5}\right)$ on relative bird abundance in a single regression, controlling for the other pollutants, fixed effects, and temperature and precipitation (Fig. 2). We focus on these two pollutants as they are the two most commonly found to cause health and mortality risks in humans. Ozone is strongly negatively associated with bird abundance (Fig. 2A). One standard deviation (SD) increase in ozone concentrations (8.4 parts per billion) is associated with a $0.117 \mathrm{SD}$ decrease in bird abundance [P $<0.01,1 \mathrm{SD}$ bird counts per checklist $=98.4$ ], and the relationship is linear over the range of ozone levels in our dataset. We find no evidence for an association with $\mathrm{PM}_{2.5}$. Importantly, this initial analysis of contemporaneous (i.e., "month-of') effects of pollution on relative abundance of birds does not capture longer-term damage caused by pollution.

We next investigate avian responses to changing ozone levels in response to the $\mathrm{NO}_{\mathrm{x}}$ Budget Trading Program (NBP), which imposes a cap on emissions of ozone precursors from May $1^{\text {st }}$ through September $30^{\text {th }}$. The NBP has affected approximately 1,000 combustion units in the Eastern and Midwestern U.S. starting in 2003 (Fig. 1). To estimate the impact of the NBP, we use a "triple difference" approach that explores treatment-versus-control comparisons along three dimensions: (1) states that participated in the NBP versus states that did not, (2) summer months when the NBP restrictions are in place versus winter months when they are not, and (3) years after 2003 when the NBP came into effect versus years before it went into effect (Deschenes, Greenstone, and Shapiro, 2017). In combination, these comparisons allow us to isolate the changes in pollution and bird abundance that are specific to NBP-affected states and specific to months when the NBP market is operating (Supplementary Information). The triple difference approach is robust to differential trends in bird abundance due to differences in species composition in NBP states versus control states. For example, the triple difference approach allows us to still estimate the causal effect of the NBP despite the observed differential declines in western versus eastern birds (Rosenberg et al., 2019). The critical assumption is that, in the absence of the NBP program, the difference in summer bird abundance trends between NBP and control states would have evolved similarly to the difference in winter trends. 

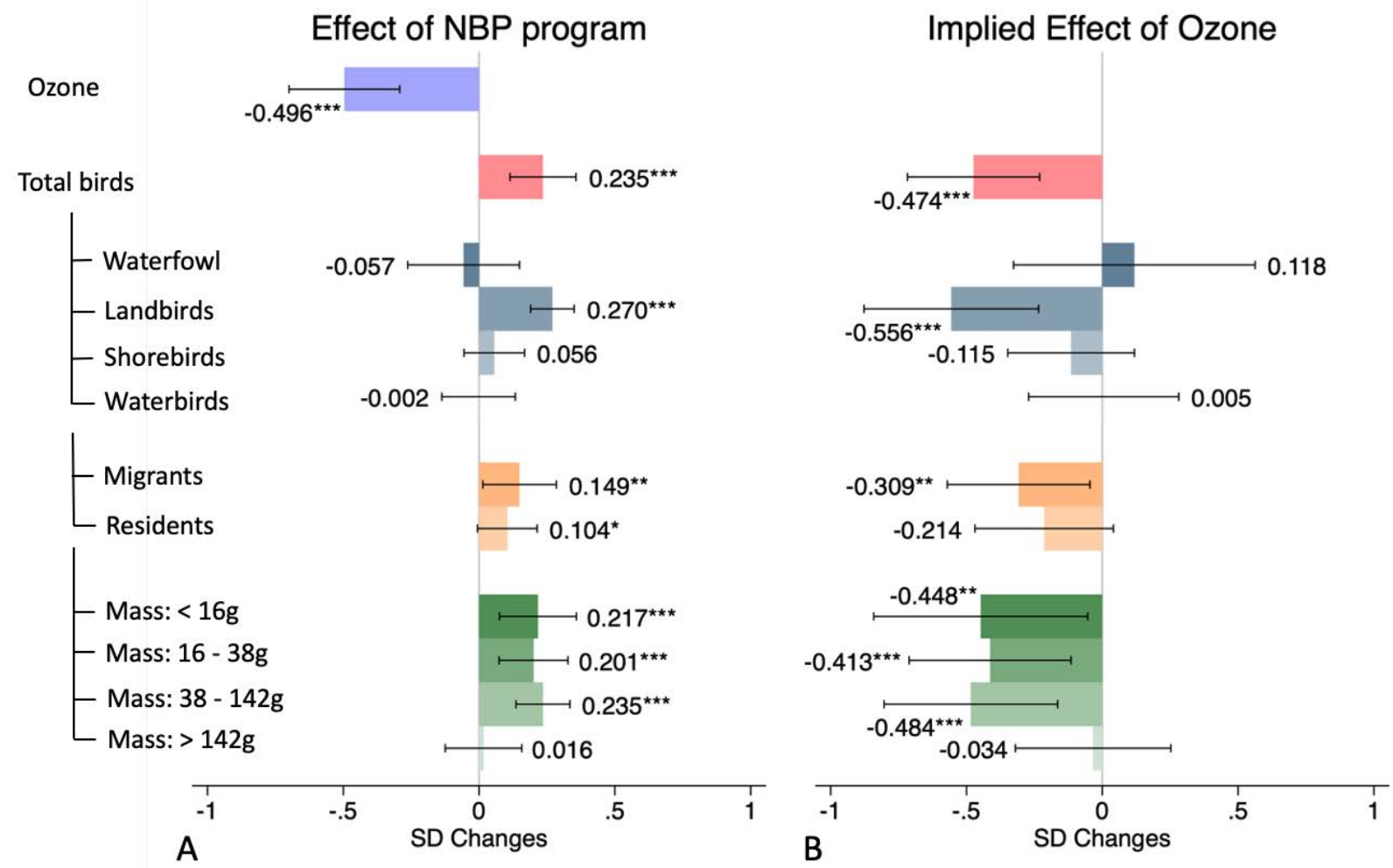

Fig. 3. (A) Effects of the NOx Budget Trading Program on ozone and bird abundance in standard deviation units. (B) Implied effects of ozone from results in (A), as calculated using an instrumental variable approach that combines the effect of the $\mathrm{NO}_{\mathrm{x}}$ Budget Program on ozone and the effect of predicted ozone on bird abundance. Birds are classified into groups following Rosenberg et al. (2019). Bird groups by mass are divided into 4 quartiles according to their mass distribution. The black bars indicate $95 \%$ confidence intervals. Standard errors are clustered at the state-season level and robust to heteroskedasticity. The regressions are weighted by the number of checklists in a given county-year-month. The IV first stage F-statistics in estimating the effect of NBP on bird groups from the second to the last row range from 22.39 (mass: $<16 \mathrm{~g}$ ) to 22.67 (shorebird). $* * * \mathrm{p}<0.01, * * \mathrm{p}<0.05, * \mathrm{p}<0.10$.

The NBP decreased ambient ozone concentrations in the average county by 0.496 SD (4.2 parts per billion) $[\mathrm{P}<0.01]$ and increased bird abundance by $0.235 \mathrm{SD}[\mathrm{P}<0.01]$ (Fig 3A). The NBP had a positive effect on landbird abundance [0.270 SD, P $<0.01]$, while the estimated impacts on waterfowl [-0.057 SD, P = 0.585], shorebirds [0.056 SD, P = 0.327], and waterbirds [-0.002 SD, $\mathrm{P}=0.972$ ] are small and not statistically significant. In addition, we find statistically significant positive effects of the NBP on birds with a mass less than 142 grams, which is approximately the mass of a northern flicker Colaptes auratus cafer or a ring-necked dove Streptopelia capicola. Birds with mass less than 142 grams correspond to the first three quartiles of bird mass distribution 
(less than 16 grams [0.217 SD, $\mathrm{P}<0.01]$, 16-38 grams [0.201 SD, $\mathrm{P}<0.01]$, and 38-142 grams $[0.235 \mathrm{SD}, \mathrm{P}<0.01])$. We do not find evidence that birds weighing more than 142 grams are affected by the NBP [0.016 SD, $\mathrm{P}=0.819]$. This is consistent with the positive effect on landbirds, which mostly fall into the smaller bird groups (85.6\% of landbirds in our sample are less than 142 grams). One potential mechanism consistent with previous research is that ozone reduces insect abundance (Hillstrom and Lindroth, 2008), and would thus reduce abundance of landbirds which tend to be the most insectivorous group. We further find that the effect on migratory birds [0.149 $\mathrm{SD}, \mathrm{P}=0.030]$ is greater than on resident birds [0.104 SD, $\mathrm{P}=0.064]$, although the estimates are not statistically distinguishable from each other.

Our results suggest that environmental regulations primarily designed to protect human health can generate substantial conservation co-benefits for other species. To further explore the generality of bird-ozone relationships at national scales the since 1980, we use a three-pronged approach (see Supplementary Information for a full description of the Instrumental Variable approach used). First, by converting the NBP program's effects on ozone and bird abundance into the direct effect of ozone on bird abundance, we show that each 0.496 SD increase in ozone is associated with a 0.235 SD decrease in bird abundance (Fig. 3A), translating to a $0.235 / 0.496=0.474$ SD decrease in bird abundance for every one SD increase in ozone (Fig. 3B). Second, we simulate a back-ofthe-envelope counterfactual scenario in which ambient ozone pollution is held constant at its 1980 level, the year when ozone was first measured and regulated by EPA, instead of following the actual pollution trajectories driven by air quality regulations like the NBP and Clean Air Act. Third, we then compare this counterfactual with recent estimates by Rosenberg et al. (2019), who reported the loss of 2.9 billion birds from 1970 to 2018.

Ozone has, on average, declined by 0.13 parts per billion per year between 1980 and 2018, with the largest declines seen in the eastern states that were regulated by the NBP (Fig. 4B). In the absence of regulation-driven ozone reductions between 1980 and 2018, bird populations would have declined by an additional 1.5 billion: $50 \%$ more than if ozone concentrations had remained the same (Fig. 4A). As such, 20\% of the current bird population of approximately 7 billion individuals can thus be attributed to improvements in ozone concentrations over the past 40 years. The observed and counterfactual bird trends begin diverging more rapidly in the 2000s when 
pollution regulation policies, such as the NBP, accelerated ambient ozone concentration improvements.
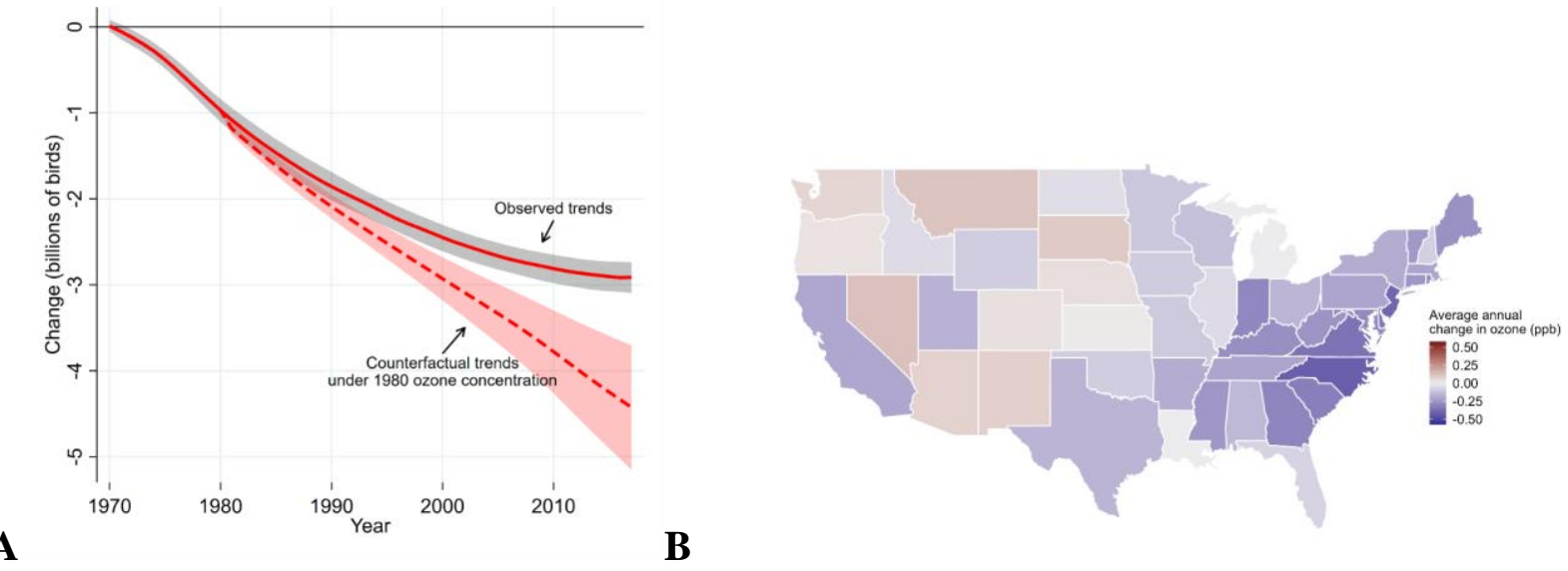

Fig. 4. (A) shows the observed trend in bird populations from Rosenberg et al. (2019) as a solid line and the counterfactual trend if ozone concentrations held at their 1980 levels as a dashed line. The shaded areas correspond to the $95 \%$ confidence interval for each where the $95 \%$ confidence intervals are derived from the cluster-robust standard errors associated with the top estimate in Fig. 3B. (B) shows the state-wide average annual change in ozone concentrations at U.S. EPA monitors between 1980 and 2018. Blue indicates decreases in ozone; red indicates increases in ozone.

Several points on the interpretation of our abundance-decline results bear mentioning. Birds' responses to air pollution are likely to occur through a number of mechanisms and at a number of different timescales. We expect some mechanisms may result in rapid effects, for example, reduced ability to forage, movement to a less optimal local habitat, or the death of birds in poorer health. However, some mechanisms may take time, such as increased mortality of healthier birds due to long-term accumulation of pollution throughout a year, or reduced reproductive productivity due to poorer body condition. The measures of relative bird abundance will reflect a combination of these short-term and long-term processes.

Although we are unable to pin down the exact mechanisms in this study, we can rule out several alternative explanations. First, our results are unlikely to be explained by reduced visibility or detectability of birds during high-ozone events. Ozone is a part of smog, but is effectively invisible. The visibility effects of smog come from particulates like $\mathrm{PM}_{2.5}$ (e.g., black carbon), which we 
have controlled for in our regressions (Fig. 2 and Table S4). Also, most bird detections during surveys are based on auditory, not visual, cues (e.g., songs, calls) making visibility less of an issue for detection. Second, it is possible that high levels of ozone may cause birds to hide or reduce their propensity to sing, and thus reduces the likelihood that they are spotted. However, these hiding behaviors are most likely to be transient, as it is not feasible for birds to change their behavior at a monthly scale - they need to forage, defend territories, and feed their young. Therefore, even if an extreme ozone event did affect behavior briefly, effects would not be consistent over the month, which is the time frame of our analysis. Finally, we note our findings are not explained by a change in human birding effort, such as time spent birding, or distance traveled, which we controlled for in constructing the abundance measure (Fig. 1).

As individual countries and the global community writ large struggle to address a multitude of complex social and environmental problems with limited resources, we are challenged to identify interventions that can deliver benefits on multiple fronts. We have shown that air quality improvements in the US have significantly stemmed the decline in bird populations. This suggests that further improvements in air quality could meaningfully contribute to efforts to halt or reverse widespread declines in wildlife populations. We contend that these conservation co-benefits from air pollution regulation may be substantial.

Although our study investigated the impact of pollution regulations on bird populations, we did not examine the ultimate value of the associated changes in ecosystem services provided by more robust bird populations. These bird-provisioned ecosystem services, which include pollination, seed dispersal, insect control, and nutrient transfer, can be substantial at local and regional scales (Clucas et al., 2014; Kolstoe and Cameron, 2016; Haefele et al., 2019). Yet these co-benefits are rarely acknowledged in cost-benefit analyses of air pollution regulation, though they are clearly required for accurate assessment of the full suite of benefits. Fully estimating the economic value of species conservation is imperative to the design and implementation of well-designed air pollution policy. This work provides a first step toward quantifying these values. 


\section{Methods:}

\section{Data}

Our data on bird counts come from the eBird Reference Dataset (ERD). The ERD is a citizen science dataset consisting of reports from eBird users detailing information on characteristics of their birding trips as well as the species and quantity of birds seen. We call each separate report of birds in the dataset a "checklist."

Our data on pollution come from the U.S. Environmental Protection Agency's Air Quality System database, which documents ground monitor readings of ambient pollution levels. ${ }^{1}$ We measure pollution concentrations for each county by spatially averaging readings from all monitors within 20 miles of the county's centroid, with the inverse of distance as weights. We use data on states' NOx Budget Trading Program (NBP) regulation status from Deschenes, Greenstone, and Shapiro (2017).

\section{Methods: Bird Abundance Estimation}

Our basis for estimating bird abundance is a database of 11 million eBird checklists across the United States. These data reflect birding effort and preferences in addition to objective bird counts. Controlling for birding checklist characteristics is thus important for recovering bird abundance (Boakes et al., 2010; Sullivan et al., 2014; Xue et al., 2016). We estimate the relationship between bird abundance and air pollution by first adjusting for birder effort in the eBird dataset.

We begin by using complete checklists in the eBird data to predict the average count of birds in a county-month-year (e.g. May 2015 in Orange County, CA) conditional on reported characteristics of the checklist and effort by the birder group. We model bird counts in the eBird data as a Poisson process that is jointly determined by a function $f$ of birder effort, detectability of birds, true bird abundance, and a random component $\varepsilon$ (Sauer and Link, 2011):

$$
\text { \# birds observed }=\exp \{f(\text { effort, detectibility, abundance, } \varepsilon)\} \text {. }
$$

To take this model to the data, we proxy for effort and detectability using data reported in the eBird checklists:

$$
\begin{aligned}
& \text { \# birds observed } \text { cohdmy } \\
& \qquad \quad \exp \left(\beta_{\mathrm{d}} \text { hours }_{\text {cohdmy }}+\beta_{\mathrm{n}}\right. \text { number of observers } \\
& \left.\qquad \text { cohdmy }+\zeta_{\mathrm{h}}+\Gamma_{\text {cmy }}+\varepsilon_{\text {cohdmy }}\right) .
\end{aligned}
$$

The left-hand side is the number of birds reported in an eBird checklist by birder group o in county $\mathrm{c}$, at hour of day h, on day of month $\mathrm{d}$, in month of year $\mathrm{m}$, and in year $\mathrm{y}$. The control variables in the Poisson model address different margins for how observers can affect the number of birds they

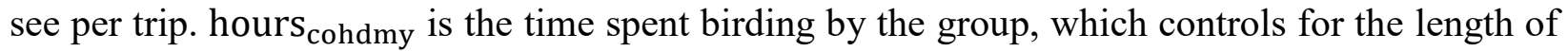
time spent observing. number of observers cohdmy $_{1}$ is the number of people in the group, which addresses the group's intensity at any given time. $\zeta_{h}$ is an hour-of-day fixed effect that controls for

\footnotetext{
${ }^{1}$ https://aqs.epa.gov/aqsweb/airdata/download_files.html
} 
all variables common across days within an hour of day, such as average bird detectability or ability to observe birds in day versus night; these controls address differential bird activity or observer ability to detect birds depending on the time of day. $\varepsilon_{\text {cohdmy }}$ is the random error term.

We are interested in the $\Gamma_{\text {cmy }}$ estimates, i.e., the county-by-month-by-year fixed effects, which captures bird abundance at the county-month-year level after conditioning on the effort variables and hour-of-day fixed effect.

To operationalize the estimation, we log-linearize the Poisson equation and estimate the model with ordinary least squares (Sauer and Link, 2011):

$$
\begin{aligned}
\log (\# \text { birds observed } & \text { cohdmy } \\
& =\beta_{\mathrm{d}} \text { hours } \\
\text { cohdmy } & +\beta_{\mathrm{n}} \text { number of observers } \\
\text { cohdmy } & +\zeta_{\mathrm{h}}+\Gamma_{\text {cmy }}+\varepsilon_{\text {cohdmy }} .
\end{aligned}
$$

We then recover the estimated fixed effects $\hat{\Gamma}_{\mathrm{cmy}}$, which are our measures of bird abundance in each county-month-year.

The choice of model specification in equation (1) is meant to be simple and transparent, and it does not capture all effort margins. Importantly, because our goal is to estimate how bird abundance changes with air quality rather than bird abundance per se, the effort adjustment variables included in the estimation need not be comprehensive as long as the omitted determinants of eBird counts from equation (1) do not systematically correlate with month-over-month changes in air pollution. As we detail further below, Table S3 reports that our estimation results are robust to alternative model specifications, such as models using raw bird counts per checklist without any effort or detectability adjustments, or models with data-driven variable choice (Least Absolute Shrinkage and Selection Operator, LASSO) using a large set of potential effort variables.

Methods: The Association Between Air Pollution and Bird Abundance (Ordinary Least Squares)

After we have recovered an estimate of $\hat{\Gamma}_{\mathrm{cmy}}$, we estimate the following model with (weighted) ordinary least squares for results reported in Fig. 2 and SM Table S2 Panel A:

$$
\begin{gathered}
\operatorname{std}(\hat{\Gamma})_{\mathrm{cmy}}=\beta_{\text {ozone }} \operatorname{std}(\text { ozone })_{\mathrm{cmy}}+\beta_{\mathrm{PM}} \operatorname{std}\left(\mathrm{PM}_{2.5}\right)_{\mathrm{cmy}} \\
+\mathrm{g}\left(\text { weather }_{\mathrm{cmy}}, \omega\right)+\theta_{\mathrm{sy}}+v_{\mathrm{cy}}+\sigma_{\mathrm{sc}}+\epsilon_{\mathrm{cmy}} .
\end{gathered}
$$

The left-hand-side variable std $(\hat{\Gamma})_{\mathrm{cmy}}$ is the estimated adjusted bird count at the county-monthyear level, standardized to mean zero and standard deviation one (i.e., a z-score) so that coefficient estimates are more easily interpretable. Our variables of interest are std(ozone) cmy $_{\text {and }}$ $\operatorname{std}\left(\mathrm{PM}_{2.5}\right)_{\mathrm{cmy}}$, standardized monthly average concentrations of ozone and fine particulate matter. We use the standardized values so that we can compare the relative magnitudes of $\beta_{\mathrm{ozone}}$ and $\beta_{\mathrm{PM}}$, since the different pollutants have different units of measurement. The coefficients can be interpreted as the standard deviation change in bird abundance from a 1 standard deviation increase in ozone or particulate matter. $\mathrm{g}\left(\right.$ weather $\left._{\mathrm{cmy}}, \omega\right)$ is a set of weather variables-average daily temperature and precipitation in a county-year-month - that flexibly control for how weather may 
affect pollutant concentrations and bird abundance. For temperature, we include 10 bins corresponding to each decile of the temperature distribution; for precipitation, we include 5 bins corresponding to each quintile of the precipitation distribution. $\theta_{\text {sy }}$ is a set of season-by-year fixed effects that control for common characteristics of seasons in all counties in a year, such as weather or pollution seasonality. $v_{c y}$ is a set of county-by-year fixed effects that control for unobserved factors common within a county in a given year, such as county-level conservation policies, county average annual trends in pollution, or county-level year-to-year changes in habitat. $\sigma_{\mathrm{sc}}$ is a set of season-by-county fixed effects that control for county-specific seasonal fluctuations in pollution and other factors that may affect bird abundance. This model specification is adapted from Deschenes, Greenstone, and Shapiro (2017), who used the exact same set of controls, combined with an Instrumental Variable approach (which we discuss below), to study the impact of the NBP program on human healthcare use and health outcomes, $\epsilon_{\mathrm{cmy}}$ is the error term. In all specifications, the estimated standard errors are robust to heteroskedasticity and clustered at the state-season level which allows for arbitrary correlation in the error term within a state-season. We weight observations by the number of checklists in a county-year-month.

Several econometric assumptions are required for estimates of $\beta_{\text {ozone }}$ and $\beta_{\mathrm{PM}}$ to be unbiased and consistent. The first assumption is that $\mathrm{E}\left[\operatorname{std}(\text { ozone) })_{\mathrm{cmy}} \times \epsilon_{\mathrm{cmy}} \mid\right.$ controls, fixed effects $]=0$ and $\mathrm{E}\left[\operatorname{std}\left(\mathrm{PM}_{2.5}\right)_{\mathrm{cmy}} \times \epsilon_{\mathrm{cmy}} \mid\right.$ controls, fixed effects $]=0$. In words, variation in air pollution is orthogonal to omitted determinants of bird abundance after conditioning on the weather controls and the set of fixed effects we included in equation (2). If an omitted variable is time-invariant (e.g., location) or varying within a county annually (e.g., year-over-year changes in annual migration patterns), it is controlled for by the county-by-year fixed effects. If an omitted variable is a recurring seasonal trend within a county (e.g., breeding behavior in the summer), it is controlled for by the county-by-season fixed effects. If an omitted variable is varying over time in a way that is common across all counties (e.g. federal conservation policy), it is controlled for by the season-by-year fixed effects. For our first econometric assumption to be violated, there must be a variable omitted from the regression that is correlated with both pollution and our estimates of bird abundance $\widehat{\Gamma}_{\text {cmy }}$ while also varying within a county, within each year, and within each season.

The second econometric assumption is that there is no non-classical measurement error induced by the effort adjustment procedure such that it becomes correlated with pollution conditional on our OLS controls and fixed effects. We can write the $\hat{\Gamma}_{\text {cmy }}$ estimate as a combination of the true $\log$ average bird abundance in a county-month-year $\log \left(\# \widetilde{b \imath r} d s_{c m y}\right)$, and measurement error $\varepsilon_{c m y}^{\Gamma}$ which may be a function of other variables that we do not control for in estimating equation (1):

$$
\widehat{\Gamma}_{\mathrm{cmy}}=\log \left(\# \widetilde{\operatorname{bird}} s_{c m y}\right)+\varepsilon_{c m y}^{\Gamma} .
$$

Our second econometric assumption states that $E\left[\varepsilon_{c m y}^{\Gamma} \times \operatorname{std}(\text { ozone })_{\text {cmy }} \mid\right.$ controls, fixed effects $]=0$ and $E\left[\varepsilon_{c m y}^{\Gamma} \times \operatorname{std}\left(\mathrm{PM}_{2.5}\right)_{\mathrm{cmy}} \mid\right.$ controls, fixed effects $]=0$. In equation (3), any systematic errors in our estimates of bird abundance that occurs at the county-year level (e.g. we systematically over or underestimate actual bird abundance in Los Angeles County in 2006) will be controlled for by 
county-by-year fixed effects. If the error systematically occurs at the county-season level (e.g. we systematically over or underestimate actual bird abundance in Los Angeles County every summer) it will be controlled for by the county-by-season fixed effects. If the error systematically occurs across all counties in a given season (e.g. we systematically over or underestimate bird abundance in all counties in Summer 2009) it will be controlled for by season-by-year fixed effects. The econometric assumption is thus similar to the previous one: that any omitted variable correlated with actual bird abundance (which will be captured by $\varepsilon_{c m y}^{\Gamma}$ in equation (3)) is not varying within a county, within each year, and within each season, after controlling for the weather variables.

Under these econometric assumptions, $\beta_{\text {ozone }}$ and $\beta_{\mathrm{PM}}$ reflect changes in bird abundance given changes in ozone and $\mathrm{PM}_{2.5}$. Importantly, these assumptions do not require estimation of the true "level" of abundance, only that any variation in estimated bird abundance that is correlated with pollution, after conditioning on the weather controls and fixed effects, is not caused by other factors.

While the validity of these assumptions cannot be directly tested, we report two sets of robustness checks in SM Tables S2 and S3. First, we report $\beta_{\text {ozone }}$ (both OLS estimates and Instrumental Variable estimates as detailed below) from a range of alternative fixed effects in the estimation of equation (3), such as state-by-year fixed effects, quarter-of-sample fixed effects, and/or month-ofsample fixed effects. Second, we estimate alternative versions of equation (1) using different effort-adjustment specifications - such as using raw bird counts per birding checklist without effort adjustments, a Poisson regression without log-linearization, models with data-driven choice (Least Absolute Shrinkage and Selection Operator, LASSO) of effort variables - and we report $\beta_{\text {ozone }}$ estimates with these alternative effort-adjustment specifications.

In the next section, we describe an instrumental variable (IV) approach to estimate the impact of the U.S. EPA's NOx Budget Trading Program (NBP) on air pollution, bird abundance, as well as the implied effect of air pollution on bird abundance. Unlike the OLS approach which uses all variation in ozone after parsing out fixed effects and weather controls, the IV approach further restricts to policy-induced pollution variation. Under the assumption that the NBP is a valid instrument for air pollution (i.e., the NBP strongly affects air pollution, and it influences bird abundance only through changes in air pollution), the IV provides consistent estimates of $\beta_{\text {ozone }}$ that are free from omitted variable and classical measurement error concerns.

Methods: The Effect of the $\mathrm{NO}_{\mathrm{x}}$ Budget Trading Program (Instrumental Variables)

In Fig. 3 and SM Table S2 Panel B we employ an instrumental variables (IV) approach. The IV serves two general purposes. First, it tells us the impact of the NBP on air pollution and bird abundance. Second, under the exclusion restriction assumption that NBP affects bird abundance only through its impact on air pollution, the IV approach overcomes potential omitted variable bias and classical measurement error problems we mentioned in the previous section, and it yields consistent estimates, i.e., that the estimator converges in probability to the true parameter value, of the impact of air pollution on bird abundance (Wooldridge, 2010).

In the first stage of the IV we estimate the effect of the NBP on monthly average ozone: 


$$
\operatorname{std}(\text { ozone })_{\mathrm{cmy}}=\beta_{\mathrm{NBP}} 1\left(\mathrm{NBP}_{\mathrm{cmy}}\right)+\mathrm{g}\left(\text { weather }_{\mathrm{cmy}}, \omega\right)+\theta_{\mathrm{sy}}+v_{\mathrm{cy}}+\sigma_{\mathrm{sc}}+\xi_{\mathrm{cmy}}^{\mathrm{st}^{\mathrm{st}} \text { stage }}
$$

std(ozone) $)_{\text {cmy }}$ is the standardized monthly average ozone concentration in county c, month-ofyear $\mathrm{m}$, and year $\mathrm{y} .1\left(\mathrm{NBP}_{\mathrm{cmy}}\right)$ is an indicator variable equal to 1 if county $\mathrm{c}$ is in a state under NBP regulation and if the current month-year is one where the NBP is in effect. ${ }^{2}$ The rest of the variables are identical to the previous equation. $\xi_{\mathrm{cmy}}^{1^{\text {st }} \text { stage }}$ is the error term. $\beta_{\mathrm{NBP}}$ is the effect of the NBP on ozone concentrations and is the top estimate in Fig. 3A.

In the second stage of the IV we estimate the effect of predicted ozone from the previous equation on adjusted bird counts:

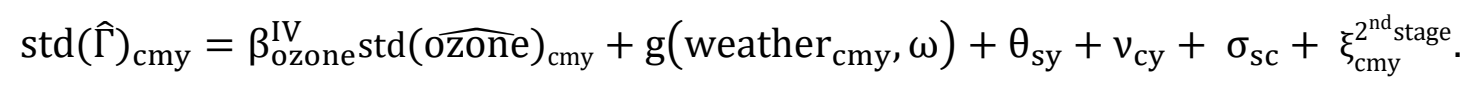

$\beta^{\mathrm{IV}}$ ozone recovers the effect of ozone on bird abundance using variation in ozone concentrations generated by the NBP. Results from this specification are plotted in Fig. 3B. Depending on the outcome, $\operatorname{std}(\hat{\Gamma})_{\text {cmy }}$ accounts for either total bird counts, waterfowl, landbirds, shorebirds, waterbirds, migrants, residents, birds with mass under $16 \mathrm{~g}$, birds with mass $16-38 \mathrm{~g}$, birds with mass $38-142 \mathrm{~g}$, or birds with mass over $142 \mathrm{~g}$.

The rest of the estimates in Fig 3A come from the reduced form version of the IV, where we regress adjusted bird counts directly on the NBP indicator variable and our set of controls and fixed effects:

$$
\operatorname{std}(\widehat{\Gamma})_{\mathrm{cmy}}=\beta_{\mathrm{NBP}} 1\left(\mathrm{NBP}_{\mathrm{cmy}}\right)+\mathrm{g}\left(\text { weather }_{\mathrm{cmy}}, \omega\right)+\theta_{\mathrm{sy}}+v_{\mathrm{cy}}+\sigma_{\mathrm{sc}}+\xi_{\mathrm{cmy}}^{\text {reduced form }} .
$$

This estimates the effect of the NBP directly on the abundance of different bird groups.

Methods: Trends in the Bird Population under Counterfactual Pollution Levels

In Fig. 4A, we compute trends in the total bird population under the counterfactual scenario in which the ground-level ozone concentration is held constant at its 1980 level. The trends are computed using the following steps.

First, we estimate annual trends in ozone concentrations between 1980 and 2018. We begin with monitor-year level ozone concentrations, and we use the following equation to estimate year-toyear changes:

\footnotetext{
${ }^{2}$ This is essentially a triple difference strategy that compares counties in and out of NBP-affected states, summer season (May through September) and non-summer season, before and after year 2003. We use one year (2002) of pretreatment data, which is the first year when eBird data became available. In unreported analysis, we have confirmed that both our OLS and IV findings are qualitatively unchanged if we drop 2002 data and instead use a double difference strategy (NBP and non-NBP counties, summer and non-summer seasons). These additional results are available upon request. We prefer the triple difference strategy as it helps address pre-existing differences in pollution and bird abundance across the treatment and comparison groups prior to the introduction of the NBP program. Any year-toyear changes in data quality from 2002 are accounted for by county-by-year fixed effects.
} 


$$
\text { Ozone }_{\mathrm{iy}}=\sum_{\tau=1980}^{2018} \beta_{\tau} 1(\mathrm{y}=\tau)+\alpha_{\mathrm{i}}+\eta_{\mathrm{iy}} .
$$

The dependent variable is the average 8 -hour concentration of ozone at monitor $\mathrm{i}$ in year $\mathrm{y}$. Because monitors differ by their initiation date, we include monitor fixed effects $\left(\alpha_{\mathrm{i}}\right)$ to account for crosssectional differences in average pollution levels across monitors in the unbalanced panel. $\eta_{\text {iy }}$ is the error term. Intuitively, the $\beta_{\tau}$ 's (with the regression constant added back) tell us the average annual level of ozone across all monitors by exploiting variation within a monitor and over time.

Next, for each year since 1980, we calculate the percentage difference between the estimated ozone level and the 1980 level: $\left(\frac{\beta_{1980}-\beta_{\tau}}{\beta_{1980}}\right) \times 100$. The predicted percentage change in bird populationthat is, the difference between the observed and counterfactual populations if ozone is held at its 1980 level — is given by:

$$
\Delta \%\left(\text { Population }_{\tau}\right)=\beta_{\text {ozone }}^{\mathrm{IV}(\%)} \times\left(\frac{\beta_{1980}-\beta_{\tau}}{\beta_{1980}}\right) \times 100,
$$

where $\beta_{\text {ozone }}^{\mathrm{IV}(\%)}$ is the percentage change in birds per 1 percentage point change in ozone, an

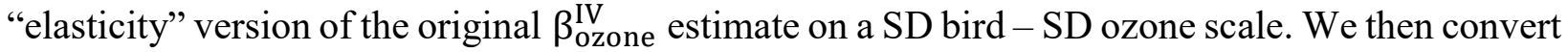
percentage population change $\Delta \%\left(\right.$ Population $\left._{\tau}\right)$ to population change $\Delta\left(\right.$ Population $\left._{\tau}\right)$ using historical population estimates provided by Rosenberg et al. (2019). The counterfactual trends are thus

$$
\text { Population }_{\tau}^{\text {counterfactual }}=\text { Population }_{\tau}^{\text {observed }}+\Delta\left(\text { Population }_{\tau}\right),
$$

where Population ${ }_{\mathfrak{\tau}}^{\text {observed }}$ is from Rosenberg et al. (2019). To derive the $95 \%$ confidence interval of the counterfactual trends, we repeat the steps above while using the upper/lower $95 \%$ confidence

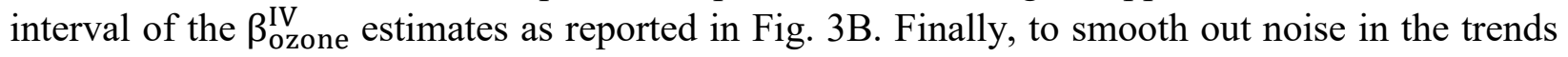
estimates due to year-to-year fluctuations in ozone levels, we estimate a locally weighted regression (LOWESS) of Population ${ }_{\mathfrak{\tau}}^{\text {counterfactual }}$ on $\tau$ and plot the smoothed value in Fig. 4A. 


\section{References:}

1. Dockery, D.W. et al. 1993. New England Journal of Medicine, 329(24): 1753-1759.

2. Pope III, C.A. et al. 2002. JAMA, 287(9): 1132-1141.

3. Chen, Y. et al. 2013. Proceedings of the National Academy of Sciences, 110(32): 12936-12941.

4. Dominici, F. et al. 2014. Science, 344(618): 257-259.

5. Schlenker, W. and W. R. Walker. 2016. The Review of Economic Studies, 83(2): 768-809.

6. Landrigan, P. J. et al. 2018. The Lancet, 391(10119): 462-512.

7. Deryugina, et a. 2019. American Economic Review, 192(12): 4178-4219.

8. Chay, K. et al. 2003. Journal of Risk and Uncertainty, 27(3): 279-300.

9. Deschênes, D. et al. 2017. American Economic Review, 107(10): 2958-89.

10. Rombout, P.J.A. et al. 1991. Environmental Research, 54(1): 39-51.

11. Llacuna, S. et al. 1993. Archives of Environmental Contamination and Toxicology, 24(1): 59-66.

12. Brown, R.E. et al. 1997. Environmental Health Perspectives, 105(2): 188-200.

13. Cuesta, N. et al. 2005. Journal of Histochemistry \& Cytochemistry, 53(6): 773-780.

14. Sanderfoot, O.V. and Holloway, T. 2017. Environmental Research Letters, 12(8): 083002.

15. Grooten, M. and Almond, R.E.A. 2018. Living Planet Report-2018: Aiming Higher.

16. Díaz, S. et al. 2020. Intergovernmental Science-Policy Platform on Biodiversity and Ecosystem Services.

17. Morrison, M.L. 1986. Current Ornithology: 429-451.

18. Gregory, R.D. et al. 2003. Ornis Hungarica, 12(13): 11-24.

19. Niemi, G.J. and McDonald, M.E. 2004. Annual Review of Ecology, Evolution, and Systematics, 35:89-111.

20. Burger, J. and Gochfeld, M. 2004. EcoHealth, 1(3): 263-274.

21. Newman, J.R. 1979. Biological Conservation, 15(3): 181-190.

22. Gilmour, M.I et al. 2001. Environmental Health Perspectives, 109(4): 619-622.

23. Loomis, D et al. 2013. Lancet Oncology, 14(13): 1262.

24. Isaksson, C. et al. 2017. Frontiers in Ecology and Evolution 5: 44.

25. Salmon, P. et al. 2018. Science of the Total Environment, 622: 635-643.

26. Rosenberg, K.V et al. 2019. Science, 366(6461): 120-124.

27. Agathokleous et al. 2020. Science Advances 6(33):eabc1176.

28. Hillstrom and Lindroth. 2008. Insect Conservation and Diversity. 1(4):233-241.

29. Sullivan, B.L et al. 2009. Biological Conservation 142: 2282-2292.

30. Sauer, J.R. and Link, W.A. 2011. The Auk, 128(1): 87-98.

31. Clucas, B. et al. 2014. Urban Ecosystems, 18(1): 251-266.

32. Kolstoe, S. and T.A. Cameron. 2016. Ecological Economics, 137: 1-12.

33. Haefele, M. et al. 2019. Ecological Economics, 157: 321-331.

\section{Methods References:}

34. Sullivan, B.L. et al. 2014. Biological Conservation, 169:31-40.

35. Boakes, E.H. et al. 2010. PLoS Biology 8.

36. Xue, Y. et al. 2016. May. Proceedings of the 2016 International Conference on Autonomous Agents \& Multiagent Systems: 776-785.

37. Fink, D. et al. 2016. The eBird Reference Dataset, Version 2016.

38. Wooldridge, J.M. 2010. Econometric Analysis of Cross Section and Panel Data. MIT press. 


\section{Supplemental Information for: \\ Conservation Co-Benefits from Air Pollution Regulation}

\section{Supplementary Text}

\section{$\underline{\text { Summary Statistics }}$}

Table S1 displays summary statistics for the data. Since pollution monitors are not in every county we have fewer pollution observations than bird abundance observations.

\section{$\underline{\text { Robustness and Sensitivity Checks: OLS and IV Fixed Effects }}$}

Table S2 shows the robustness of our main results when using different sets of fixed effects to control for different kinds of unobservable variables and using alternative levels of clustering to control for arbitrary within-cluster correlation in error terms. Our results are highly robust to the choice of fixed effects except in the case of month-of-sample and county-by-month fixed effects for the OLS approach where the estimates are attenuated. Our results are also robust to whether we cluster at the summer-state level, or more conservatively at just the state level. In all cases the Kleibergen-Paap F-Statistic suggests the instrument is strong.

\section{$\underline{\text { Robustness and Sensitivity Checks: Bird Abundance Estimation Method }}$}

Table S3 shows the robustness of our OLS and IV results when using alternative approaches to log-linearization when estimating bird abundance. Column 1 shows results from the simplest approach where we use the average number of birds per checklist for each county-year-month without any effort or detectability adjustments. Column 2 corresponds to using equation (1) to estimate bird abundance, where it is estimated using Poisson Pseudo Maximum Likelihood instead of log-linearizing the equation. Column 3 corresponds to our preferred log-linearized approach for comparison. Column 4 uses LASSO to select a set of effort and detectability variables to include. In this approach, we include all possible interactions of linear, quadratic, and cubic functions of hours, numbers of observers, distance covered, and area covered. We also include the set of 24 hour-of-day fixed effects, a dummy variable for if distance covered was 0 indicating that the checklist corresponds to a stationary count, and a dummy variable for if there was just one observer for the checklist. Estimates are strongly negative across all possible specifications for both the OLS and IV approach.

\section{$\underline{\text { Robustness and Sensitivity Checks: Spatial Displacement }}$}

One potential threat to our approach is that we may simply be picking up on spatial displacement where birds move into neighboring counties but are not physically harmed by the pollution itself. This would move birds from high ozone counties to low ozone counties, and, as an artifact, we would estimate a negative relationship between bird abundance and ozone. This mechanism would be a violation of the Stable Unit Treatment Value Assumption (SUTVA). We test for SUTVA 
violations in Table S4. Column 1 shows our main OLS results. Column 2 is a spatial lag model that includes additional variables capturing the average ozone and $\mathrm{PM}_{2.5}$ levels across all border counties. If there was a SUTVA violation we would expect the estimated coefficients on average border county ozone to be positive, indicating that birds are moving to avoid higher ozone levels. The negative ozone estimate indicates that there is unlikely to be a SUTVA violation. Column 3 tests for SUTVA violations in an alternative way by averaging pollution across a county and all of its border counties so it acts as a larger geographical unit. If there was a SUTVA violation we would expect this estimated coefficient to be smaller than the estimates in Column 1, however it is approximately the same size. Column 4 is similar to our main IV result with an additional variable capturing the $\mathrm{PM}_{2.5}$ level of own county. Column 5 replicates the test in Column 3 but using the IV strategy. Again, the IV estimates in Columns 4 and 5 are similar, suggesting that there is little to no spatial displacement caused by ozone that is confounding the interpretation of our results.

\section{$\underline{\text { Robustness and Sensitivity Checks: Alternative weighting of observations }}$}

Table S5 shows the robustness of our OLS and IV results when assigning sample weights using an alternative function of the number of checklists in a given county-year-month. We explore functions of the following form: sample weight $=\min$ (cap, number of checklists) where cap is some level at which we cap the maximum weight. This is in order to test whether our results are driven by a few counties with large numbers of checklists (Fig. S1A). Column 1 caps the number of checklists in the weighting to be 20, which is approximately the median in the distribution of checklist counts. Column 2 and 3 cap the number of checklists in the weighting at $90^{\text {th }}$ and $99^{\text {th }}$ percentile, which is 185 and 781 checklists respectively. Both the OLS and IV estimation results in the three columns are comparable to our preferred specification where we do not assign any specific cap at the number of checklists in the weighting. The robustness check shows that our results are not driven by a small number of counties with lots of checklists.

\section{Checklist Statistics and Locations}

Figs. S1A-S1C show the spatial distribution of checklists and birder effort. Checklist locations and effort are concentrated near population centers, illustrating the potential need for effort-adjusted counts.

\section{$\underline{\text { Species Maps }}$}

Fig. S2A-S2F shows abundance maps for six different bird species of different sizes, ranges, and seasons. The abundance distributions match closely to the distributions obtained from alternative modeling approaches like the Spatial-Temporal Exploratory Model (STEM) developed for eBird data, which provided rich geo-spatial details in the abundance estimates. The drawback of using these alternative approaches like STEM in our study context is that they often do not provide time series variation in abundance which is key to our implementation of the "within" (i.e., fixed effects) estimation that exploits month-over-month variation in air pollution. 

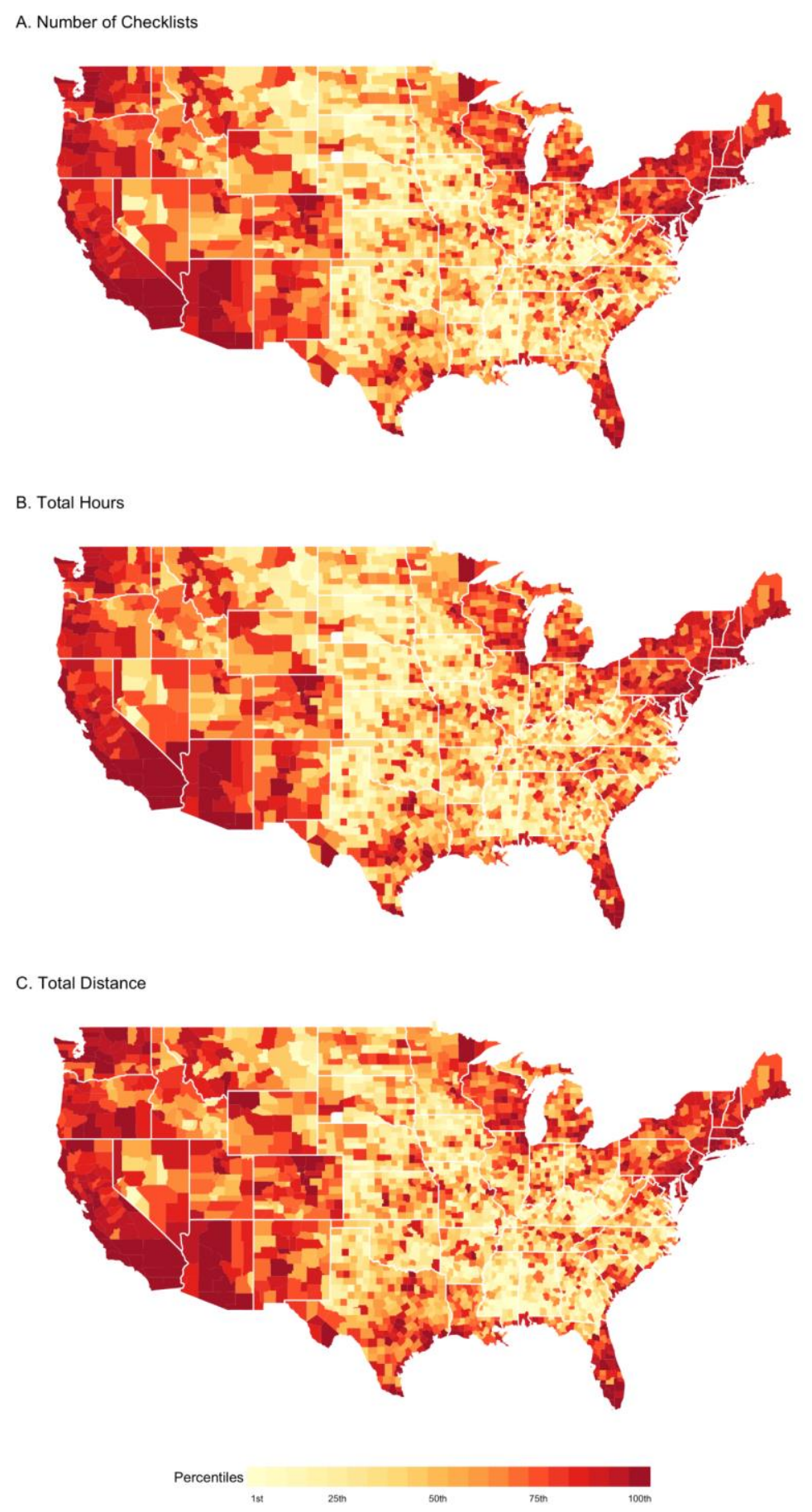

Fig. S1.

The number of eBird checklists (A), total hours spent birding (B) and total distance covered (C) per county in percentiles. 

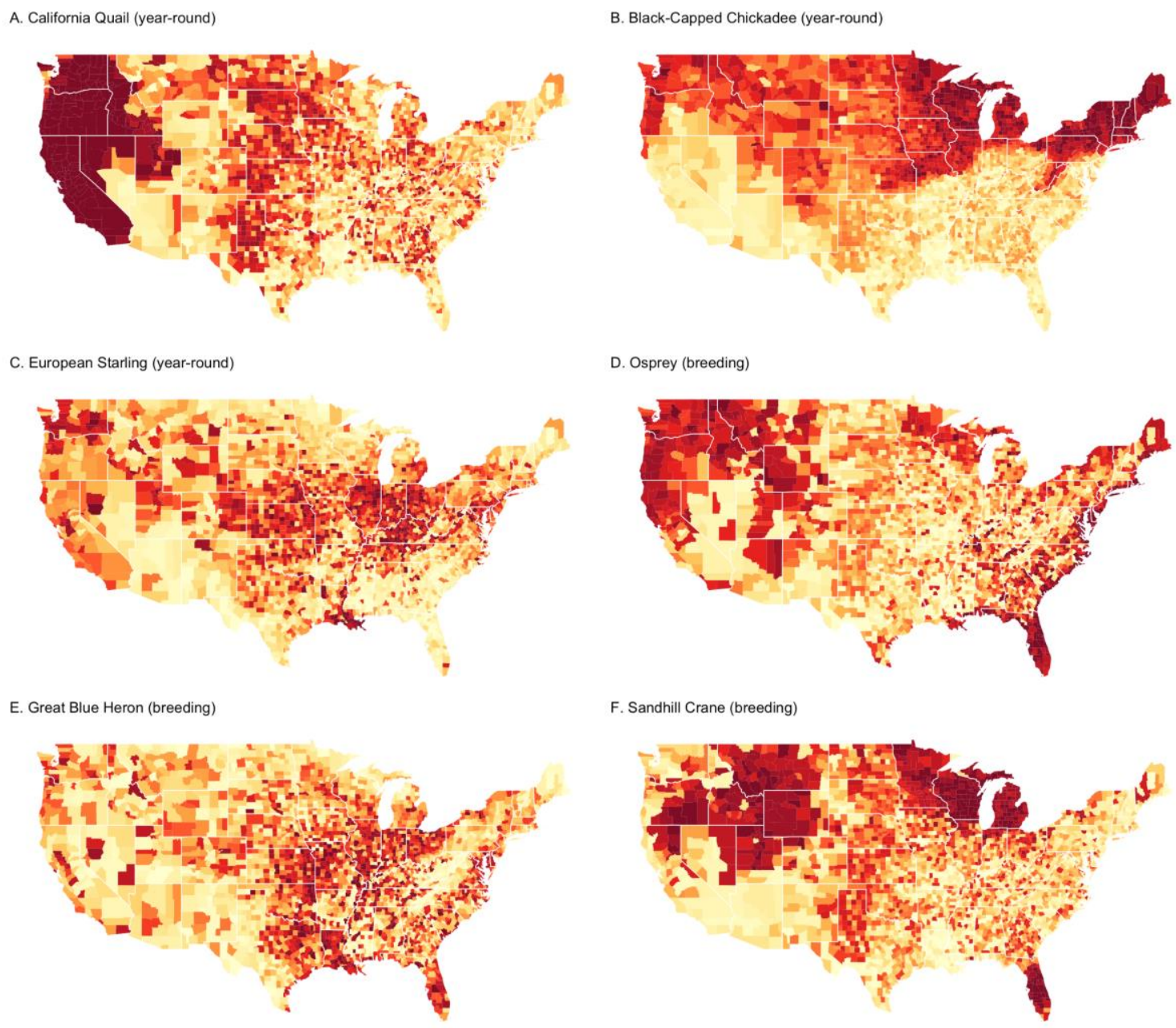

Abundance Percentiles

Fig. S2.

Year-round abundance map for California Quail (A), Black-Capped Chickadee (B), European Starling (C). Breeding season abundance map for Osprey (D), Great Blue Heron (E), and Sandhill Crane (F). County colors indicate ventiles of bird abundance across all years. Darker colors indicate greater abundance.

Note: Counties in the lower ventiles often all have effectively zero abundance. For example, outside the top ventile for California Quail, all counties have effectively 0 observations in the checklist and variation in color is just statistical noise. 
Summary statistics.

\begin{tabular}{|c|c|c|c|}
\hline & (1) & (2) & (3) \\
\hline & Observations & Mean & S.D. \\
\hline Total number of checklists & 276,685 & 41.04 & 113.87 \\
\hline Birding time per checklist (hours) & 276,685 & 1.62 & 1.57 \\
\hline Number of observers per checklist & 276,685 & 2.08 & 3.31 \\
\hline Most common birding time of day & 276,685 & 8 AM & - \\
\hline Total bird counts per checklist & 276,685 & 149.61 & 227.42 \\
\hline Migrants & 279,764 & 120.14 & 191.54 \\
\hline Residents & 279,663 & 9.54 & 10.73 \\
\hline Waterfowl & 279,797 & 21.70 & 52.36 \\
\hline Landbirds & 279,526 & 59.79 & 68.78 \\
\hline Shorebirds & 280,197 & 4.07 & 12.86 \\
\hline Waterbirds & 279,934 & 21.23 & 53.78 \\
\hline Mass: $<16 \mathrm{~g}$ & 279,853 & 8.83 & 11.93 \\
\hline Mass: $16-38 g$ & 279,780 & 18.54 & 23.55 \\
\hline Mass: $38-142 \mathrm{~g}$ & 279,575 & 30.20 & 43.89 \\
\hline Mass: $>142 \mathrm{~g}$ & 279,879 & 39.88 & 82.32 \\
\hline Air Quality Index (AQI) & 207,210 & 40.19 & 13.27 \\
\hline Ozone & 157,091 & 0.03 & 0.01 \\
\hline $\mathrm{SO}_{2}$ & 105,177 & 1.89 & 2.01 \\
\hline $\mathrm{CO}$ & 78,967 & 0.36 & 0.22 \\
\hline $\mathrm{NO}_{2}$ & 82,048 & 9.73 & 6.01 \\
\hline $\mathrm{PM}_{2.5}$ & 156,742 & 9.43 & 3.74 \\
\hline
\end{tabular}

Table S1. The number of observations in column 1 is the number of county-by-year-by-monthlevel observations for each variable. The analysis drops the largest $1 \%$ bird counts within each bird group to eliminate outlier counts. 
OLS (Panel A) and IV (Panel B) specifications varying the fixed effects included in the model.

\begin{tabular}{|c|c|c|c|c|c|c|c|}
\hline & $(1)$ & 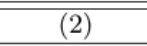 & 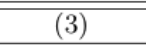 & $(4)$ & $(\overline{c(5)}$ & 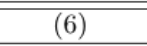 & 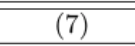 \\
\hline \multicolumn{8}{|l|}{ Panel A: OLS } \\
\hline Standardized Monthly Average Ozone & $\begin{array}{c}-0.1146^{* * *} \\
(0.0112)\end{array}$ & $\begin{array}{c}-0.1166^{* * *} \\
(0.0121)\end{array}$ & $\begin{array}{c}-0.0468^{* * *} \\
(0.0119)\end{array}$ & $\begin{array}{c}-0.0513^{* * *} \\
(0.0126)\end{array}$ & $\begin{array}{l}-0.0055 \\
(0.0077)\end{array}$ & $\begin{array}{l}-0.0079 \\
(0.0073)\end{array}$ & $\begin{array}{c}-0.1166^{* * *} \\
(0.0133)\end{array}$ \\
\hline Observations & 93,408 & 92,072 & 93,282 & 91,924 & 92,498 & 91,068 & 92,072 \\
\hline \multicolumn{8}{|l|}{ Panel B: NBP IV } \\
\hline Standardized Monthly Average Ozone & $\begin{array}{c}-0.2981 \\
(0.3124)\end{array}$ & $\begin{array}{c}-0.4737^{* * *} \\
(0.1240)\end{array}$ & $\begin{array}{c}-0.4463^{*} \\
(0.2317)\end{array}$ & $\begin{array}{c}-0.4982^{* * *} \\
(0.1231)\end{array}$ & $\begin{array}{c}-0.3527 \\
(0.3151)\end{array}$ & $\begin{array}{c}-0.5520^{* * *} \\
(0.1772)\end{array}$ & $\begin{array}{c}-0.4737^{* * *} \\
(0.1473)\end{array}$ \\
\hline Observations & 116,667 & 114,810 & 116,525 & 114,626 & 115,557 & 113,511 & 114,810 \\
\hline Weather controls & $\mathrm{Y}$ & $\mathrm{Y}$ & $\mathrm{Y}$ & $\mathrm{Y}$ & $\mathrm{Y}$ & $\mathrm{Y}$ & $\mathrm{Y}$ \\
\hline State $\times$ Year FE & $\mathrm{Y}$ & & Y & & $\mathrm{Y}$ & & \\
\hline County $\times$ Year FE & & Y & & Y & & Y & $\mathrm{Y}$ \\
\hline Summer $\times$ Year FE & $\mathrm{Y}$ & $\mathrm{Y}$ & & & & & $\mathrm{Y}$ \\
\hline County $\times$ Summer FE & Y & Y & & & & & $\mathrm{Y}$ \\
\hline Quarter-of-sample FE & & & $\mathrm{Y}$ & $\mathrm{Y}$ & & & \\
\hline County $\times$ Quarter FE & & & $\mathrm{Y}$ & $\mathrm{Y}$ & & & \\
\hline Month-of-sample FE & & & & & $\mathrm{Y}$ & $\mathrm{Y}$ & \\
\hline County $\times$ Month FE & & & & & $\mathrm{Y}$ & $\mathrm{Y}$ & \\
\hline IV First Stage F-statistics & 19.53 & 22.65 & 36.23 & 23.61 & 19.20 & 11.66 & 15.63 \\
\hline
\end{tabular}

Table S2. The entries in Panel A are the coefficient estimates of the associations between air pollution and bird abundance using ordinary least squares regressions. The entries in Panel B are the coefficient estimates from the triple difference estimator. Column 2 is the preferred specification. Additional control variables are listed at the bottom of this table. Reported standard errors are clustered at the state-season level in column 1-6. In column 7, the reported standard errors are clustered at the state level. Standard errors are robust to heteroskedasticity. The regressions are weighted by the number of checklists in a given county-year-month. The data used is from 2002 to 2016 for 1,900 counties. Both bird count and air pollution variables are standardized to be mean zero, SD one. All regressions use binned temperature and precipitation as weather controls. ${ }^{* * *} \mathrm{p}<.01, * * \mathrm{p}<.05,{ }^{*} \mathrm{p}<.10$. 
OLS (Panel A) and IV (Panel B) specifications varying the effort adjustment method.

\begin{tabular}{|c|c|c|c|c|}
\hline Effort Adjustment Method: & $\begin{array}{c}1(1) \\
\text { No Adjustment }\end{array}$ & $\begin{array}{c}(2) \\
\text { Poisson }\end{array}$ & $\begin{array}{c}(3) \\
\text { Log-Linear }\end{array}$ & $\begin{array}{c}(4) \\
\text { Post-LASSO } \\
\text { Log-Linear }\end{array}$ \\
\hline \multicolumn{5}{|l|}{ Panel A: OLS } \\
\hline Standardized Monthly Average Ozone & $\begin{array}{c}-0.1324^{* * *} \\
(0.0080)\end{array}$ & $\begin{array}{c}-0.1903^{* * *} \\
(0.0101)\end{array}$ & $\begin{array}{c}-0.1166^{* * *} \\
(0.0121)\end{array}$ & $\begin{array}{c}-0.1284^{* * *} \\
(0.0124)\end{array}$ \\
\hline Observations & 104,202 & 92,121 & 92,072 & 92,072 \\
\hline \multicolumn{5}{|l|}{ Panel B: NBP IV } \\
\hline Standardized Monthly Average Ozone & $\begin{array}{c}-0.2482^{* *} \\
(0.1176)\end{array}$ & $\begin{array}{c}-0.4337^{* * *} \\
(0.1620)\end{array}$ & $\begin{array}{c}-0.4737^{* * *} \\
(0.1240)\end{array}$ & $\begin{array}{c}-0.3442^{* * *} \\
(0.1227)\end{array}$ \\
\hline Observations & 113,511 & 114,810 & 116,667 & 114,810 \\
\hline Abundance Estimation Model Adj. $\mathrm{R}^{2}$ & - & 0.3070 & 0.2856 & 0.3491 \\
\hline No. of Effort Variables in Abundance Estimation & - & 26 & 26 & $(275) 27$ \\
\hline IV First Stage F-statistics & 24.00 & 22.70 & 22.65 & 22.65 \\
\hline
\end{tabular}

Table S3. The entries in Panel A are the coefficient estimates of the associations between air pollution and bird abundance using ordinary least squares regressions. The entries in Panel B are the coefficient estimates from the triple difference estimator. Column 1 is from regressing the number of birds observed on county-month-year fixed effects to estimate bird abundance. Column 2 corresponds to estimating the multiplicative version of equation (1) with Poisson Pseudo Maximum Likelihood to estimate bird abundance. Column 3 is the preferred specification and corresponds to using equation (1) to estimate bird abundance. Column 4 corresponds to equation (1) but uses LASSO with 10-fold cross validation to select the set of control variables to address effort and detectability. All regressions use county-by-year, summer-by-year, county-by-summer fixed effects, and binned temperature and precipitation as weather controls. Reported standard errors are clustered at the state-season level and are robust to heteroskedasticity. In column 4, LASSO selected 27 out of 275 possible effort variables. The regressions are weighted by the number of checklists in a given county-year-month. The data used are from 2002 to 2016 for 1,900 counties. Both bird count and air pollution variables are standardized to be mean zero, SD one. $* * * \mathrm{p}<.01, * * \mathrm{p}<.05, * \mathrm{p}<.10$ 
OLS and IV estimates testing spatial displacement of birds and Stable Unit Treatment Value Assumption violations.

\begin{tabular}{|c|c|c|c|c|c|}
\hline & $\begin{array}{l}\text { (1) } \\
\text { OLS }\end{array}$ & $\begin{array}{l}(2) \\
\text { OLS }\end{array}$ & $\begin{array}{l}(3) \\
\text { OLS }\end{array}$ & $\begin{array}{l}\text { (4) } \\
\text { IV }\end{array}$ & $\begin{array}{l}(5) \\
\text { IV }\end{array}$ \\
\hline Standardized Monthly Average Ozone of Own County & $\begin{array}{c}-0.1166^{* * *} \\
(0.0121)\end{array}$ & $\begin{array}{c}-0.0459^{*} \\
(0.0271)\end{array}$ & & $\begin{array}{c}-0.3890^{* * *} \\
(0.1178)\end{array}$ & \\
\hline Standardized Monthly Average PM2.5 of Own County & $\begin{array}{l}-0.0056 \\
(0.0054)\end{array}$ & $\begin{array}{c}-0.0234^{* * *} \\
(0.0078)\end{array}$ & & $\begin{array}{c}-0.0529^{* *} \\
(0.0229)\end{array}$ & \\
\hline Standardized Monthly Average Ozone of Border Counties & & $\begin{array}{c}-0.0745^{* *} \\
(0.0290)\end{array}$ & & & \\
\hline Standardized Monthly Average PM2.5 of Border Counties & & $\begin{array}{c}0.0237^{* *} \\
(0.0095)\end{array}$ & & & \\
\hline Standardized Monthly Average Ozone of Own and Border Counties & & & $\begin{array}{c}-0.1206^{* * *} \\
(0.0124)\end{array}$ & & $\begin{array}{c}-0.4597^{* * * *} \\
(0.1430)\end{array}$ \\
\hline Standardized Monthly Average PM2.5 of Own and Border Counties & & & $\begin{array}{c}0.0012 \\
(0.0061)\end{array}$ & & $\begin{array}{c}-0.0715^{* * *} \\
(0.0280)\end{array}$ \\
\hline $\begin{array}{l}\text { Observations } \\
\text { IV First Stage F-statistics }\end{array}$ & 92,072 & 89,695 & 89,695 & $\begin{array}{c}92,072 \\
16.20\end{array}$ & $\begin{array}{c}89,695 \\
13.34\end{array}$ \\
\hline
\end{tabular}

Table S4. The entries in Column 1-3 are the coefficient estimates of the associations between air pollution and bird abundance using ordinary least squares regressions. The entries in Column 4-5 are the coefficient estimates from the instrumental variable design. All regressions use countyby-year, summer-by-year, county-by-summer fixed effects, and binned temperature and precipitation as weather controls. Reported standard errors are clustered at the state-season level and are robust to heteroskedasticity. The regressions are weighted by the number of checklists in a given county-year-month. The data used are from 2002 to 2016 for 1,900 counties. Both bird count and air pollution variables are standardized to be mean zero, SD one. $* * * \mathrm{p}<.01, * * \mathrm{p}<$ $.05, * \mathrm{p}<.10$. 
OLS (Panel A) and IV (Panel B) specifications varying the weighting of observations.

\begin{tabular}{lccc}
\hline \hline & $(1)$ & $(2)$ & $(3)$ \\
& Cap weight at 20 & Cap weight at $90^{t h}$ percentile & Cap weight at $99^{t h}$ percentile \\
\hline Panel A: OLS & $-0.1002^{* * *}$ & $-0.1111^{* * *}$ & $-0.1150^{* * *}$ \\
Standardized Monthly Average Ozone & $(0.0100)$ & $(0.0104)$ & $(0.0115)$ \\
& 92,072 & 92,072 & 92,072 \\
Observations & & & $-0.4811^{* * *}$ \\
& & $-0.5614^{* * *}$ & $(0.1225)$ \\
Panel B: NBP IV & $-0.5429^{* * *}$ & $(0.1289)$ & 114,810 \\
Standardized Monthly Average Ozone & $(0.1664)$ & 114,810 & 23.25 \\
Observations & 114,810 & 26.79 & \\
\hline IV First Stage F-statistics & 23.13 & & \\
\hline \hline
\end{tabular}

Table S5. The entries in Panel A are the coefficient estimates of the associations between air pollution and bird abundance using ordinary least squares regressions. The entries in Panel B are the coefficient estimates from the instrumental variable design. All regressions use county-byyear, summer-by-year, county-by-summer fixed effects, and binned temperature and precipitation as weather controls. Reported standard errors are clustered at the state-season level and are robust to heteroskedasticity. The regressions are weighted by the number of checklists in a given countyyear-month. Column 1 caps the number of checklists in the sample weighting to be 20, which is roughly the median. Column 2 caps the number of checklists in the weighting at the $90^{\text {th }}$ percentile, which is 185 checklists. Column 3 caps the number of checklists in the weighting at the $99^{\text {th }}$ percentile, which is 781 checklists. The data used is from 2002 to 2016 for 1,900 counties. Both bird count and air pollution variables are standardized to be mean zero, SD one. All regressions use binned temperature and precipitation as weather controls. ${ }^{* * *} \mathrm{p}<.01,{ }^{* *} \mathrm{p}<.05,{ }^{*} \mathrm{p}<.10$. 